\title{
The impact of automation in IT industry: Evidences from India
}

\author{
Feby C Varghese ${ }^{1}$, Dr. T. A. Ashok Kumar ${ }^{2}$ \\ Institute of Management, Christ University, Bengaluru, India ${ }^{1}$ \\ Assistant Professor, Institute of Management, Christ University, Bengaluru, India ${ }^{2}$
}

\begin{abstract}
Robotic Process Automation is the next big thing in the outsourcing industry. So major Indian IT companies are in the bandwagon of RPA which give the flexibility, speed, accuracy and avoid any human error than can happen. But how well the employees respond to this change? To understand this an exploratory research was done in and around Bengaluru. The subject were mainly employees of top IT companies like Infosys, TCS, Wipro, Accenture, HCL etc, which mainly deals with outsourcing services. In the view of software companies, which primarily cater to the outsourcing and ITes services, the entire shift should be changed from low skill cheap human resource to process automation which will also help in overall cost reduction. Process Automation will remove the human error in the execution. It also bring speed and accuracy to the existing process which will be very much crucial to the client and curtailing the competition. This means the client can be provided with a better customer experience, which is scalable and flexible. The company can also draw insights into the services provide and the analytics will help in better optimisation of process automation which will result in overall decrease in the cycle time.
\end{abstract}

Keywords: Automation, Outsourcing, domain, cost reduction.

\section{INTRODUCTION}

India is the world's largest sourcing destination, accounting for approximately 55 per cent of the US\$ 146 billion market. The country's cost competitiveness in providing Information Technology (IT) services, which is approximately 3-4 times cheaper than the US, continues to be its Unique Selling Proposition (USP) in the global sourcing market. India's highly qualified talent pool of technical graduates is one of the largest in the world and is available at a cost saving of 60-70 per cent to source countries. This large pool of qualified skilled workforce has enabled Indian IT companies to help clients to save US\$ 200 billion in the last five years. India's IT industry amounts to 12.3 per cent of the global market, largely due to exports. Export of IT services accounted for 56.12 per cent of total IT exports (including hardware) from India. The Business Process Management (BPM) segment accounted for 23.46 per cent of total IT exports during FY15. The IT-BPM sector is estimated to expand at a CAGR of 9.5 per cent to US $\$ 300$ billion by 2020 .

While initial development of India's software industry was based primarily on bodyshopping work onsite at U.S. firms, in recent years the trend has been increasingly for Indian firms to conduct software development for U.S. clients "offshore" in India. This shift was the result of a maturing of India's software industry and its international reputation in the last 15 years, and the development of necessary infrastructure and communications technologies in India that has made offshore work possible[2].

As the Indian software industry matured, increasing client confidence in Indian capabilities and quality standards enabled Indian firms to move their work offshore. With maturity, has come a goal to move up the value chain. Many new companies were set up in the 1980 s by entrepreneurs with ambitions of creating world-class software development centres. Firms which had started primarily as subcontractors for technical manpower gradually shifted to managing complete parts or phases of projects, and then to delivering complete solutions from India.[5]

But one thing that threatens the model of Indian IT sector is Automation. According to a research conducted by the World Bank in 2016, it is expected that about 69 per cent of jobs in India is under threat due to automation. This is mainly because the traditional methods followed by the industries may not help in achieving the requirements of the future. The emergence of new technologies will disrupt the market and bring in lot of changes. There can be two major effect, one it will make the traditional jobs which the industry followed throughout the year irrelevant and second it will create new job opportunities based on the new skill set required in the market.[8]

Most large IT services companies have been investing in automation of processes in their traditional businesses like business process outsourcing (BPO) and application and infrastructure management, which means fewer engineers will be required at the lower end of the pyramid. At the turn of the century, a boom in the IT sector led by companies such as TCS, Infosys and Wipro translated into the creation of thousands of white collar jobs in the country, and a relatively easy opportunity to work onsite 
in the mature markets of US and Europe. Since these companies were involved in mundane jobs such as infrastructure management, server maintenance and client support, they hired in huge numbers from engineering colleges across the country.[4]

It is estimates that $80 \%$ of offshore IT jobs and $30 \%-40 \%$ of finance and accounting jobs in India will be eliminated by robotic process automation, which is the application of technology to process a transaction and carry out other tasks.[3]

Robotic Process Automation aims to use an automated system to manipulate existing application software (CRMs, ERPs, help desk and claim applications) in the same way that a person works with those systems and the presentation layer to perform a specific task. The use of the word "robotic" to describe this rapidly growing field is somewhat misleading. Currently, the phrase "robotic process automation" is used to refer to the use of sophisticated computer software that automates rule-based processes without the need for constant human supervision and not something based on artificial intelligence.[8][9]

The major benefits of this system are they are cost effective and fast. They cost only one third as a full-time employee and can work 24/7 without the need for breaks. They are also scalable and can increase or decrease the system parameters based upon the requirements. It also eliminates the human error in calculation because they work based on pre-set rules or parameters and have great attention to details. With the evolution of Big data analytics, the automated system will be helpful to create real-time analytics which will be helpful in carrying out decision at a rapid pace compared with the traditional system followed, which is time consuming and is prone to error.[6][7]

In this research paper, the focus is on the possibility of job loss due to automation and how well the industry is prepared for it. The research is mainly done by collecting data from the people working in the industry for several years and familiar with the latest trends that affect the industry. The scope of the research is limited to the immediate impact of automation and does not cover further developments in automation like incorporating artificial intelligence. The study is conducted mainly in the city of Bengaluru, which is the IT hub of India and the consideration is more on the Indian outsourcing \& ITes sector. The study will also look in to the nature of job loss, since it is estimated that the most affected area will be the entry level jobs which required to be substantiated by primary data.

\section{RELATED WORKS}

The term "Robotic Process Automation" (RPA) connotes visions of physical robots wandering around offices doing the job of humans. However, the term really means automation of service tasks. In a paper published in 2015,
Bhattacharjee \& Chakrabarti [1] argue that in the future of the Indian IT outsourcing industry is uncertain. This uncertainty emanates from paucity of quality manpower, inability of the industry to move up the value-chain, underdeveloped state of the domestic market and unpreparedness of the industry for disruptive technologies.

These factors may erode the competitive advantage of the industry and inhibit the growth momentum. Johannes [7] in his paper published in 2016 states that Shortening software release cycles increasingly becomes a critical competitive advantage as today's users, customers, and other stakeholders expect quick responses to occurring issues and feature requests. DevOps practices and Cloud computing are two key paradigms to tackle these issues by enabling rapid and continuous delivery of applications, utilizing automated software delivery pipelines. According to Jämsä-Jounela, Sirkka-Liisa[10] in an article title Future trends in process automation says that the importance of automation in the process industries has increased dramatically in recent years. In the highly industrialized countries, process automation serves to enhance product quality, master the whole range of products, improve process safety and plant availability, efficiently utilize resources and lower emissions. In the rapidly developing countries, mass production is the main motivation for applying process automation. The greatest demand for process automation is in the chemical industry, power generating industry, and petrochemical industry; the fastest growing demand for hardware, standard software and services of process automation is in the pharmaceutical industry. The importance of automation technology continues to increase in the process industries. The traditional barriers between information, communication and automation technology are, in the operational context, gradually disappearing. New application fields like biotechnology and microtechnology pose challenges for future theoretical work in the modeling, analysis and design of control systems.

\section{RESEARCH METHODOLOGY}

Robotic Process Automation is the next big thing in the outsourcing industry. So major Indian IT companies are in the bandwagon of RPA which give the flexibility, speed, accuracy and avoid any human error than can happen. But how well the employees respond to this change? To understand this an exploratory research was done in and around Bengaluru. The subject were mainly employees of top IT companies like Infosys, TCS, Wipro, Accenture, HCL etc, which mainly deals with outsourcing services. The main outcomes expected from the research are:

1. The awareness about RPA

2. Preparedness for a transition

3. Practicality of RPA implementation

4. Worker attitudes to RPA

5. Challenges Faced in implementation

6. Client side support 
Each aspect need to be look upon inorder to gain insight of how the tech industry in india is prepared for the change which affect majority of its work force.

As part of the study, the Skill level of the job, Percentage of job that can be automated, Possibility to simplify job, New Opportunities, Customer Satisfaction as Independent Variable and the impact of automation as the dependent variable. A hypothesis was formulated with

H0: there is no significant impact of automation on Software Industry.

H1: there is significant impact of automation on Software Industry.

\section{IV.DATA ANALYSIS \& INTERPRETATION}

The study was mainly conducted keeping in mind an age group of 20 to 40 . These demographics will help to get real insight into the entry level to the mid-level employees.
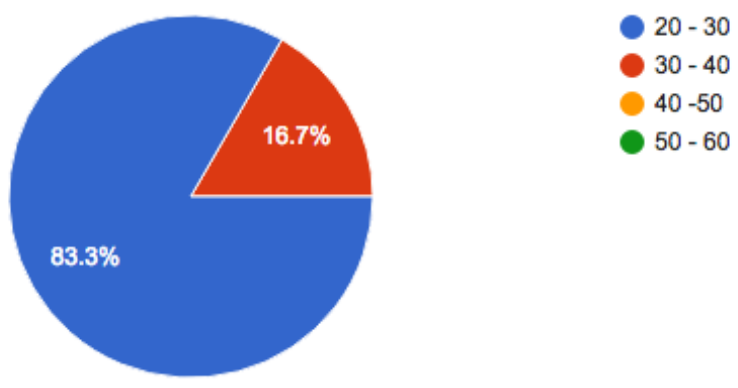

About $83.3 \%$ of the respondents here are within the age of 20 to 30 and are low-level employees. The rest, which account for about $16.7 \%$ are in the age range of 30 to 40 and are mostly mid-level employees.

All the respondents possess an under-graduate or post graduate degree and are well qualified to take up their particular job.

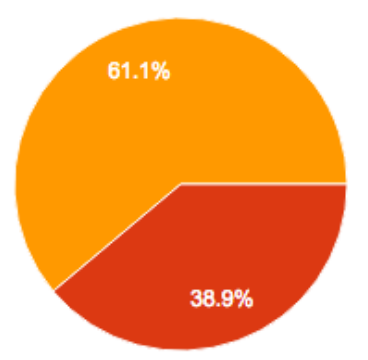

School Level

Under-Graduate

Post-Graduate

PhD

Other

The majority of the respondents $(61.1 \%)$ has a postgraduate degree and the rest $(38.9 \%)$ has an undergraduate degree. This population include both mid-level and low-level employees.

The income level of the employees also vary based on the level they are in. The range includes income of less than 3 lakh INR to more than 10 lakh INR.
The majority of the respondents $(33.3 \%)$ are having an income of less than 3 lakh INR, which signifies that they are low-level employees. The mid-level employees which account for about $16.7 \%$ has an income of more than 10 lakh INR.

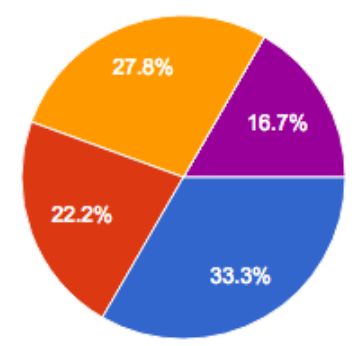

Less than 3lakh

3 Lakh to 5 Lakh

5 Lakh to 8 Lakh

8 Lakh to 10 Lakh

More than 10 Lakh

The nature of the job done by the respondents is analysed to get an idea of what percentage of the job can be automated. If the percentage is below $10 \%$, then automation will not have much impact on the nature of the job. Similarly, if the percentage of job that can be automated is more than $50 \%$, then that job may cease to exist in the near future.
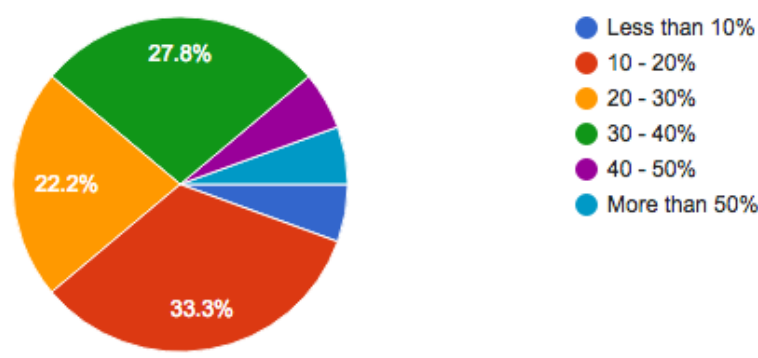

In the study, it is obtained that among the respondents, an average of 10 to $20 \%$ of job can be automated, which means that the job will exist in the future, but with a reduced man power. This means companies will hire less employees in the future and low-level employees are likely to be fired since the companies will try to optimise resources.

Based on these findings, an alternate data collection was conducted to gather the preparedness to face the challenges of the future work place. This is to understand how the employees will respond when they no longer can work in a particular domain or the job profile they were working on ceased to exist.

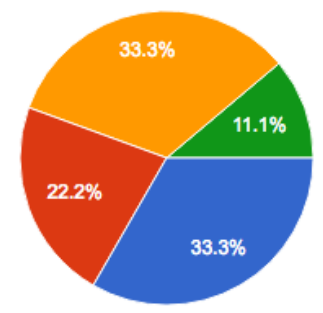

Resistance from Workers

Initial Investment

Lack of Technical Know-how

Security Concerns

Other 
It was found that about $55.6 \%$ of the population tried to gain knowledge of new domain so as to change the job role, once automation threaten their job. But the major issue here is that about $44.4 \%$ of the respondents' lack preparedness to face the challenge. This is a serious issue since process automation will happen in the future and will replace the work force. Without preparedness, these employees will be at risk and there will not be a coming back since the job profile they are working on will cease to exist in the future.

Based on this several top-level managers are interviewed to find out the challenges they face to implement automation in their company. This is important since lack of co-operation from the part of employees will be disastrous for the implementation of a system like robotic process automation. These challenges include resistance from workers, initial investment, lack of technical knowhow, security concerns etc.
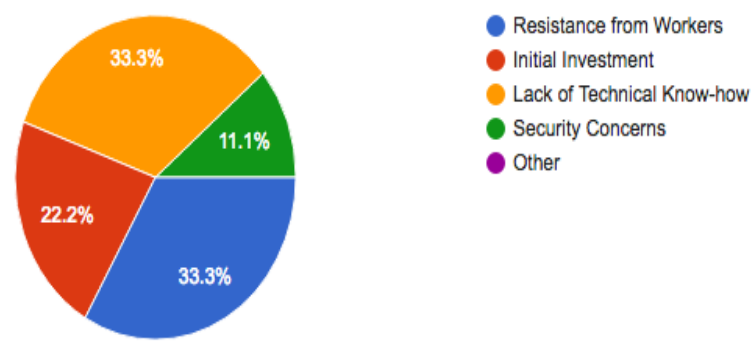

It is found out from the study that resistance from workers and lack of technical know-how are the biggest challenges top-level manager face in implementing automation in the workplace.

The employees under this study were well aware about the prospects of automation. Most of the companies are conducting training for a smooth transition to automation and some of the employees under this study were directly involved in the process. Because of this they have their own view on whether it is a threat to the job or not.

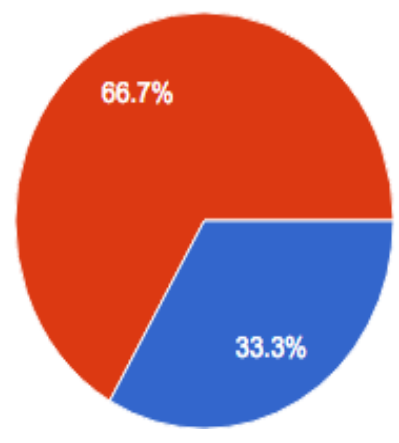

Yes No

Most of the respondents have an opinion that automation will not affect their job. This is mainly because of the human component present in the job. But it need to be substantiated, for this correlation is done on IBM SPSS.

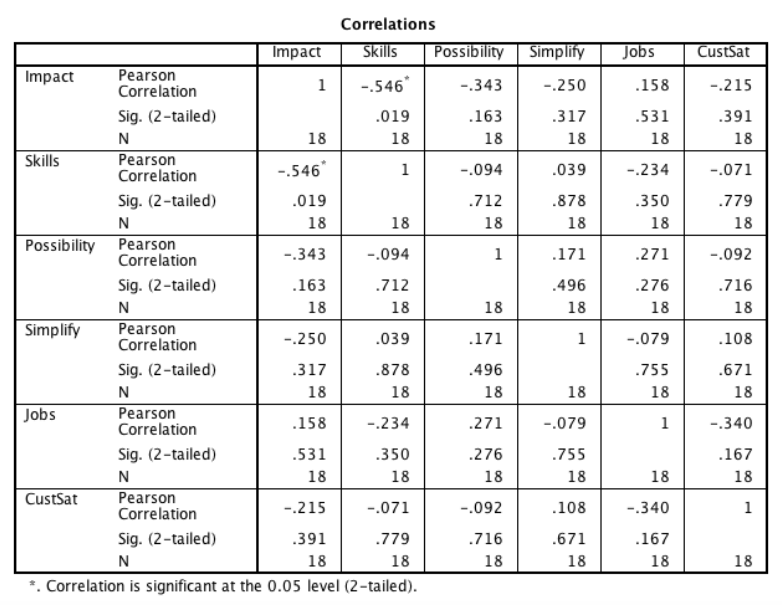

From the Pearson correlation, it can be interpreted that creation of new jobs is positively correlated with the impact of automation and all the other variables like skills required, the possibility to automate the job, the ability to simplify the job and customer satisfaction is negatively correlated.

The value .158 between impact and jobs mean that even if they are directly proportional, there is a weak relationship between the two variables. This means that changes in one variable are weakly correlated with changes in the second variable. This number is very far to 1 . For this reason, we can conclude that there is a weak relationship between impact and jobs.

Here the Sig (2-Tailed) value is greater than .05 for all the variables except skills. This means that for all the others, it can be concluded that there is no statistically significant correlation between the variables and the impact variable. So, increases or decreases in one variable do not significantly relate to increases or decreases in the other variable.

But in case of skills, the Sig (2-Tailed) value is less than .05 and it can be concluded that there is a statistically significant correlation between the impact and the skills. That means, increases or decreases in one variable do significantly relate to increases or decreases in the other variable.

\section{FINDINGS}

The major finding from this study is that because of automation, there will be an emergence of new jobs. This is because of the fact that employees with lower skill level will be most affected by automation. The areas which have less skill set will be the most affected and will cease to exist. When these fields are removed, new fields will arise to replace the old one. This is the reason why new jobs are added to the existing ones because of automation. This is a contradiction to the popular belief that automation will result in job loss. 
Comparing the impact of automation with the skill required to perform a particular job, it can be inferred from the analysis that null hypothesis is rejected, since the significance value is less than .05 .

But if we compare the impact of automation with other variables like the possibility to automate the job, the ability to simplify the job, creation of new jobs and customer satisfaction, then it can be inferred from the analysis that the null hypothesis cannot be rejected, since the significance value is greater than .05

\section{VI.CONCLUSION}

Automation as we all know will affect almost all the industries including the software industry. But the impact depends on how prepared are we to face it. In the software industry because of automation, low skilled jobs will be redundant and may cease to exist. There will be new job additions to the market because of the change in technology. But the alarming fact here is that about $44.4 \%$ of the software employees are not prepared for this change, which require learning new domain, relearning and unlearning the existing one. This study coupled with the existing fact that at least $65 \%$ of the IT recruits in India are untrainable pose a serious threat to the conventional methods followed by the companies to recruit employees.

In the view of software companies, which primarily cater to the outsourcing and ITes services, the entire shift should be changed from low skill cheap human resource to process automation which will also help in overall cost reduction. Process Automation will remove the human error in the execution. It also bring speed and accuracy to the existing process which will be very much crucial to the client and curtailing the competition. This means the client can be provided with a better customer experience, which is scalable and flexible. The company can also draw insights into the services provide and the analytics will help in better optimisation of process automation which will result in overall decrease in the cycle time.

\section{SUGGESTIONS}

The main suggestion from this study are that the landscape is changing and companies are on a hurry to grab market share by adopting process automation. Companies like Infosys, Accenture etc started to invest in Process Automation. Lot of RPA vendors cease this opportunity and educate the vendors. But as the technology changes, the inability to adapt to the change or the nature of people to remain stagnant to change is worrying to the Indian software industry as a whole. This can be overcome only by gaining new domain knowledge and work towards a more integrated approach with process automation.

For the companies, IT hiring need to be changed, since the low skilled employees may not benefit the company in the long run, coupled with the fact that $65 \%$ of the recruits are untrainable is a wake up call for the Indian IT Industry. Negliecting the challenges posed by automation will be disasterous for the indian IT Industry, since the competition in the out sourcing market is intense and other competing contries with less manpower will take it as an opportunity to shift the table to their side. Because of automation, the manpower edge that India poses in the entry-level market will be at loss. This is a serious threat to the working age population and need immediate action so as to have a sustainable growth in the future.

\section{FUTURE SCOPE}

The scope of this study was mainly limited to the impact of major factors on automation. It is done in a managerial point of view and not in a technical view. From this study, it is evident that lot of low skilled domains will cease to exist and new domain will come up. But a study on which are the domain that are likely to fall, which are the one that can sustain the automation spree and what are the emerging domain that need to be looked upon by the future employees of the software industry will be an interesting add-on to this study. This is crucial since the Indian software industry is at a crossroads because new technologies are emerging and companies are in a running spree to adopt them due to the fear that they may lose out to the competition. This need to be taken care of since the impact of each technology and the future perspective need to be understood before it is implemented. This study paves the way for a continuous research in this aspect which will be mutually beneficial for the IT companies and the employees alike. Since the research is more of a managerial view, technical issue are not covered much in this research, so a continued research in the technicality of the Robotic Process Automation will be helpful for the technically sound employees to get a better picture of the domain challenges.

\section{REFERENCES}

[1] Bhattacharjee, S., \& Chakrabarti, D. (2015). Indian IT outsourcing industry: Future threats and challenges - A reassessment. Futures, 67.

[2] Arora, A., \& Gambardella, A. (2005). The Globalization of the Software Industry: Perspectives and Opportunities for Developed and Developing Countries. Innovation Policy and the Economy, 5.

[3] Brougham, D., \& Haar, J. (2017). Smart Technology, Artificial Intelligence, Robotics, and Algorithms (STARA): Employees' perceptions of our future workplace. Journal of Management \& Organization.

[4] Otekhile, C.-A., \& Zeleny, M. (2016). Self Service Technologies: a Cause of Unemployment. International Journal of Entrepreneurial Knowledge, 4(1).

[5] Moorthi, Y.L.R. (2011). Non-linear growth: The road ahead for Indian IT outsourcing companies: The Infosys experience: In conversation with S. Gopalakrishnan, CEO and MD, Infosys Technologies. IIMB Management Review, 23(2).

[6] Mohamed, S. I. (2015). DevOps Shifting Software Engineering Strategy Value Based Perspective. IOSR Journal of Computer Engineering, 17(2)

[7] Johannes, W., Uwe, B., \& Leymann, F. (2016). ENHANCING CLOUD APPLICATION DEVOPS USING DYNAMICALLY 
TAILORED DEPLOYMENT ENGINES. International Journal of Cloud Computing, 4(1).

[8] Collier, D. A. (1983). The service sector revolution: The automation of services. Long Range Planning, 16(6).

[9] Roberts, J. (2001). Challenges facing service enterprises in a global knowledge-based economy: lessons from the business services sector. International Journal of Services Technology and Management, 2(3/4).

[10] Jämsä-Jounela, S.-L. (2007). Future trends in process automation. Annual Reviews in Control, 31(2), 211-220. http://doi.org/10.1016/j.arcontrol.2007.08.003

\section{BIOGRAPHIES}

Dr. T. A. Ashok Kumar, M.C.A, M.B.A., M. Phil., Ph.D is working as Assistant Professor in Institute of Management, Christ University, Bengaluru, India since 2015. He has completed Ph.D in Computer Science MS University, Tirunelveli, Tamilnadu, India. Also, he completed Post Graduation in MCA from SNR Sons College, Coimbatore, MBA from Bharathiar University, Coimbatore and Master of Philosophy (M.Phil) from Bharathidasan University, Tiruchi, Tamilnadu. With 17 years of teaching experience he had conducted course curriculum for various universities and autonomous colleges in Tamilnadu. He also served as Chairman \& Member of the Board of Studies in CMS College of Science \& Commerce (Autonomous), Coimbatore, Bharathair Univeristy and other various universities in Tamilnadu. He also member and editor for various International Journals in Computer Science like Inderscience Publications, SCI, AIRCC etc., His research interests are in Data Mining, focusing on Computer Networking, Distributed Computing and Human Resource Management. In addition, he has made numerous contributions to Data Mining and has examined the impact of Software Engineering Techniques and Applications on the design of various statistical models. Also, he has presented various papers in International and National Conferences.

Feby C Varghese, has done his B.Tech in Electrical and Electronics Engineering from the University of Kerala, Kerala, India. He is currently pursuing his MBA in Lean Operations and System from the Institute of Management, Christ University, Bengaluru, India. $\mathrm{He}$ is a has a Six Sigma Green Belt certification from KPMG and an advanced diploma in Industrial Automation. $\mathrm{He}$ is a winner of paper presentation competitions at national level and had published research papers in several journals including IJARCCE. 